\title{
If Intuitions Must Be Evidential then Philosophy is in Big Trouble
}

\author{
Joshua Earlenbaugh, Bernard Molyneux \\ Department of Philosophy, University of California at Davis
}

\begin{abstract}
Many philosophers claim that intuitions are evidential. Yet it is hard to see how introspecting one's mental states could provide evidence for such synthetic truths as those concerning, for example, the abstract and the counterfactual. Such considerations have sometimes been taken to lead to mentalism - the view that philosophy must concern itself only with matters of concept application or other minddependent topics suited to a contemplative approach-but this provides us with a poor account of what it is that philosophers take themselves to be doing, for many of them are concerned with the extra-mental facts about the universe. Evidentialism therefore gestates a disaster for philosophy, for it ultimately demands an epistemology for the investigation into such matter as the abstract and the modal that simply will not be forthcoming. We make a different suggestion: That intuitions are inclinations to believe. Hence, according to us, a philosophical argument does well, as a socio-rhetorical matter of fact, when it is founded on premises philosophers are generally inclined to believe, whether or not those inclinations to believe connect appropriately to the extra-mental facts. Accordingly, the role of intuitions (inclinations to believe) in philosophical methodology is non-evidential, and the question of how they could be used as evidence falls away.
\end{abstract}

Keywords: intuition, evidence, a priori, inclinations, dispositions, methodology, dispositional, mentalism

\section{Introduction}

Prima facie, the role of intuitions in philosophical inquiry is evidential. Philosophers use intuitions to decide between competing philosophical viewpoints. At the same time, it is prima facie puzzling how intuitions, mere inner mental states or events, could constitute evidence for certain kinds of external matters of fact. The deployment of modal intuitions in metaphysics,

Corresponding author's address: Bernard Molyneux, Dept Philosophy, One Shields Avenue, 2292 Social Science and Humanities, Davis, CA, 95616, USA. Email: molyneux@ucdavis.edu. 
for example, is difficult to explain on the evidentialist proposal, as it is mysterious how facts about us - that we have such and such intuitions about the necessary structure of the universe-could provide evidence of how things are across modal space. Similar points can be made, to a greater or lesser extent, about the deployment of intuitions in other sub-fields of philosophy. This puzzle is one that we address in this paper. Broadly, we argue that intuitions cannot generally be playing an evidential role in philosophy, since, for too many tasks, they appear to be unsuited. Hence, if philosophers engaged in these tasks have been using intuitions as evidence, as many claim, then they have been engaged in a disastrously misconceived enterprise.

We suggest something else: That intuitions are a subclass of inclinations to believe. ${ }^{1}$ Accordingly, we argue that they play purely heuristic and rhetorical roles in the securing of philosophical positions, helping to promote simpler, more psychologically appealing models of reality. ${ }^{2}$ The primary role of intuitions, then, is not as truth indicators, but as persuaders, and hence the problem of how they track extra-mental reality does not arise.

In section 2 of the paper we demonstrate the hopelessness of treating philosophical intuitions as evidential, showing that the evidential view cannot account for how intuitions could be successfully deployed as they are often intended to be-to secure facts about the modal, the abstract and about other of what we call "troublingly extra-mental" matters-i.e. states and affairs to which we have no known reliable access. In this we generally follow the work of Goldman and Pust (1998) and Goldman (2007), but we depart from these in that we reject all "mentalist" solutions to the effect that philosophical inquiry is concerned with mind-dependent entities (e.g. the explication of folk concepts). In section 3 we say how our own view better accounts for the role of intuitions in philosophical inquiry. In section 4 of the paper we respond to objections to our positive account.

\section{The Trouble With Evidentialism}

\subsection{Why Evidentialism Leads to Mentalism}

Alvin Goldman (1987) borrows from Strawson (1959) a distinction between descriptive and revisionary (or prescriptive) metaphysics. "[D]escriptive metaphysics is content to describe the actual structure of our thought about the world; revisionary metaphysics is concerned to produce a better structure" (Strawson 1959, 9). Accordingly, descriptive metaphysics need only ac-

1 If one thinks of philosophical intuitions as mostly being classificatory (see Kornblith 1998) then one might prefer to regard them as inclinations to judge. The distinction is immaterial to anything we discuss in this paper. Our arguments are supportive of either version.

2 Though we do not argue the matter here we hold, nonetheless, that when deployed with care, their use may be virtuous. 
count, in a systematic way, for our particular metaphysical intuitions. But revisionary or prescriptive metaphysics, according to Goldman, "tries to identify the real constituents of the world, the ones to which we ought to be ontologically committed" (Goldman 1987, 528, our emphasis). Accordingly, prescriptive metaphysics is often warranted in departing from metaphysical intuition. Goldman's objection to much contemporary metaphysics is that it blurs the distinction between descriptive and prescriptive metaphysics and, as a result, the proper evidential role of our intuitions is lost. Out intuitions would clearly be relevant if the focus were on descriptive metaphysics, for in that case the aim is to explicate our folk ontology. But if we are investigating the structure of reality and not merely people's common beliefs about it then the role of intuitions is much less clear. As Goldman puts it: "Why should we regard intuitions or feelings as reliable indicators of genuine metaphysical facts?" (Goldman 1992, 57). ${ }^{3}$

A possible genus of answer that Goldman (2007) himself suggests-as he also does with Joel Pust (Goldman and Pust 1998) - can be subsumed under the title mentalism. Mentalism is the meta-philosophical view that the objects of philosophical concern are, in some appropriate sense, mental or mind-dependent. A mentalist might hold, for instance, that epistemologists are concerned not with the phenomenon of knowledge but with the application of the concept knowledge. For example, where epistemologists like Gettier identify cases in which an agent has a justified true belief that $\mathrm{P}$ but lacks knowledge that $\mathrm{P}$, the mentalist holds that such cases are best described as cases where we are willing to apply the concept justified true belief but not the concept knowledge.

3 The worry is not unrelated to P. Benacerrafs (1973) challenge to Mathematical Platonism: (Abstract entities are causally inert, therefore, given Platonism, how could we possibly have a plausible epistemological story that accounts for mathematical justification?) Sider (2001) addresses a similar matter as it pertains to metaphysics, without resolving it, in the introduction to Four-Dimensionalism:

Anyone working on topics like mine, using the methods I use, is often asked a question something like Are you doing descriptive or prescriptive metaphysics?'... What I am doing does not fit neatly into either category... I follow the descriptive metaphysician in taking ordinary beliefs about metaphysical matters seriously, but I follow the prescriptive metaphysician in aspiring to more than autobiography. This conception of the nature of metaphysics is, I suspect, common to many of the practitioners of contemporary analytic metaphysics. Unfortunately, I also share with my fellow practitioners the lack of a good answer to a very hard follow-up question: why think that a priori reasoning about synthetic matters of fact is justified? (Sider 2001, xiv) 
Note that Goldman is not moved to mentalism because intuitions, being mental states, cannot be reliable indicators of extra-mental facts. That is not Goldman's claim. Nor should it be. Perceptions are probably best regarded as mental states, and perceptions are reliable indicators of extramental reality. Hence being mental is no bar to being a reliable indicator of extra-mental matters. Rather, Goldman's worries that there is no sufficiently obvious mechanism via which intuition could reliably connect to certain extra-mental matters of philosophical concern. When philosophers use intuition to evaluate synthetic propositions concerning abstract entities, epiphenomenal qualia or non-actual possible worlds, for example, the very nature of the targets of investigation precludes their partaking in a causal process that might be plausibly thought to be reliable. When philosophers consider other synthetic matters, such as the persistence of ordinary objects, the reality of normative facts or the existence of God, the desired mechanism is not so much precluded as it is simply hard to imagine. In either kind of case, the inquiry is undercut by fears concerning the underlying epistemology. If there is simply no clear way in which intuition could provide warrant concerning the topic in question, then what is it we think we are doing when we use intuition?

For Goldman, mentalism comes to the rescue, neatly explaining how intuitions can be used as evidence in philosophical inquiry. For we are all natural authorities on the deployment of our own psychological concepts. In deciding whether, for example, the concept knowledge applies or not in some given case, one only need ask oneself whether one would, oneself, be inclined to apply it. ${ }^{4}$ On the assumption that one has mastered the concept, questioning oneself ought to be helpful. Hence, the having of an intuition, though it is nothing more than some mental state or event, looks to be the kind of thing that could be truth indicative. It could be some conceptually revelatory form of introspection and, if the objects of philosophy are concepts and the like, that would explain its utility in philosophy.

Mentalism, however, also has a serious disadvantage in accounting for the philosophical process: It is at odds with what many philosophers earnestly take themselves to be doing. For, in many cases, philosophers take themselves to be investigating mind-independent matters across actual and possible contexts, not mind-dependent matters of concept application. Sider (2001), for instance, is pretty upfront about this:

I am after the truth about what there is, what the world is really like. So I do not want merely to describe anyone's conceptual scheme, not

\footnotetext{
4 That is not to say that this is an infallible method-others might apply the same concept differently, and one so might be at odds with one's community. Nonetheless the community as a whole can conduct its investigations from its collective armchair.
} 
even if that scheme was thrust upon us by evolution. (Sider 2001, xiv)

Surely Sider's attitude here is representative of contemporary analytic metaphysics. And that seems like the right attitude, since the philosopher who cannot decide whether some state of affairs $S$ is modally possible presumably has no difficulty applying the concept of modal possibility in general, nor any general problem applying the concepts that appear in the conception of S. In fact, in some cases, it is constitutive of the philosophical position itself that its object not be mind-dependent. For example, theistic philosophers do not regard God as existing in virtue of the way we apply the God-concept, but as existing independently of it. Similarly, many kinds of moral realist regard the moral good as existing in some mind-independent sense. One could go on and on. Clearly, then, no appropriately neutral philosophy of philosophy could classify all of its topics as mind-dependent.

Accordingly, intuitions are often used to investigate matters other than the conceptual. Philosophers, for example, may intuit that phenomenal colors are incompatible without thereby counting this as a conceptual truthi.e. as something that pragmatically follows from our disposition to apply the relevant concepts (See Bealer 1998); Nor, for a second example, is it likely that the dualist intuition about mind and body is grounded in some correct conceptual analysis, as if the concept mind simply involved not body as part of its meaning. And as a final instance, it is not a conceptual truth that objects endure, rather than perdure, the supposed intuitiveness of the former view notwithstanding.

But that puts us in a dialectical bind: The idea that philosophy seeks the application conditions of concepts is at odds with the flourishing of realist, non-mentalist philosophies of morality, God, time, space, persistence etc. But if we conclude, on the other hand, that the objects of philosophical inquiry can be mind-independent matters that extend beyond the limits of concept application then we must explain how armchair inquiry, using intuitions, can possibly provide evidence for them; in particular, how it can provide evidence concerning objects (like pure possibilia) that play no causal role in this universe, or objects (like abstract objects) that play no causal role period, or facts (like normative facts) that do not obviously involve causally potent truth-makers. Let all such things-that are not only extra-mental but which also, as far as we can gather, bear no reliable epistemic connection to the mental-be dubbed 'troublingly extra-mental facts and entities'. We hereby formulate the following argument:

1. If philosophical inquiry is typically, or at least often, concerned with troublingly extra-mental facts and entities, then intuition cannot play its supposed evidential role in philosophical inquiry 
2. Philosophical inquiry is typically, or at least often, concerned with troublingly extra-mental facts and entities.

3. Hence, intuition cannot play its supposed evidential role in philosophical inquiry.

To the extent that the reader shares with us the view that a satisfactory intuition-based epistemology for troublingly extra-mental facts and entities is not forthcoming, and to the degree that she shares with us the view that philosophers are sincere when they claim to be investigating these troublingly extra-mental facts and entities, she ought to find the argument persuasive. It leaves us with two options: Either intuition plays some other role in philosophy, which has been confused with an evidential role, or philosophers have been wrongly using intuitions as evidence for facts to which intuition could have no conceivable access, in which case whole swathes of philosophy are, in essence, a wash. We prefer to give philosophers the benefit of the doubt. We therefore pursue the former option.

\subsection{Are Arguments Against Evidentialism Self-Defeating?}

Before pressing on, note that since we have given an argument against the idea that intuitions are used, in philosophy, as evidence we ought to address the contention of Bealer (1992) and Pust (2001) that all such arguments are self-defeating. Roughly, that is because such arguments use intuitions as evidence for the conclusion that intuitions cannot be evidence. In particular, Pust contends that arguments like the one presented above take the following general form:

(1) Aside from propositions describing the occurrence of her judgments, $S$ is justified in believing only those propositions which are part of the best explanation of S's making the judgments that she makes.

(2) Propositions about philosophical topic $\mathrm{X}$ are not part of the best explanation of S's making the judgments that she makes.

(therefore)

(3) S is not justified in believing any propositions about philosophical topic X.

For instance, he describes Goldman's attack on contemporary metaphysics as being essentially, the following:

(1) Aside from propositions describing the occurrence of her judgements, $\mathrm{S}$ is justified in believing only those propositions which are 
part of the best explanation of S's making the judgements that she makes.

(2) Propositions about metaphysical topic $\mathrm{X}$ are not part of the best explanation of S's making the judgements that she makes.

(therefore)

(3) $\mathrm{S}$ is not justified in believing any propositions about metaphysical topic X.

Pust, however, takes issue with all arguments of this form on the grounds that it is difficult to see how proposition (1) could be established without appealing to the very intuitions that the argument is designed to undermine. For (1) is a principle of epistemological practice established on the basis of strong epistemic intuitions. More pointedly, the principle, if factual, is a statement of normative fact; but it is hard to see how the normative facts can play a causal or counterfactual role in the production of normative intuitions. Hence, via their own prescription, statements of form (1) look to be principles to which we are not entitled.

Since we follow Goldman in finding it unlikely that normative, abstract or other-worldly states of affairs play a role in the best explanation of how one comes to have intuitions about abstract or other-worldly states of affairs, and since we draw the same conclusion that, since they are (probably) not, we have reason to think that intuitions concerning them are not evidential, if Goldman's argument is subject to Pust's objection then so is ours.

However, this "self-defeating" argument has an unfortunate kinship with a fallacious argument once used to defend reason from its skeptics. Here is that old argument as put forth by Hume:

If the sceptical reasonings be strong, say they, it is a proof, that reason may have some force and authority: if weak, they can never be sufficient to invalidate all the conclusions of our understanding. (Hume 1896, IV: I, 145)

Similarly, one could argue (as Pust more or less does) that if arguments to the effect that intuitions are not evidential are strong then, since they are themselves based on intuitive premises, intuitions are used as evidence in strong arguments. But if such arguments are weak, then they fail to establish the conclusion that intuitions are not used as evidence. Either way, such arguments must fail.

However, later in the same passage, Hume contends that this form of argument is illegitimate, for: 
Reason first appears in possession of the throne, prescribing laws, and imposing maxims, with an absolute sway and authority. Her enemy, therefore, is obliged to take shelter under her protection, and by making use of rational arguments to prove the fallaciousness and imbecility of reason, produces, in a manner, a patent under her band and seal. (Hume 1896, IV: I, 145)

In other words, the skeptic (whether of intuitions or of reason) is entitled to use her opponent's methods in the manner of a reductio. If the method of intuition works against the method of intuition, then the method of intuition is self-defeating. Pust's argument falls to this counter, for the skeptic about intuition may indeed use intuitive epistemic maxims to undermine the warrant provided by intuition. It is a problem for the evidentialist, not for the skeptic, that if intuition evidentially supports anything, it evidentially supports epistemic maxims that deny that intuition can provide any such support.

However, the skeptic of intuitions leaves some residual dissatisfaction in taking this line, a form of dissatisfaction that, Hume noted, was residual to skepticism quite generally:

For here is the chief and most confounding objection to excessive scepticism, that no durable good can ever result from it; [the skeptic] must acknowledge, if he will acknowledge anything, that... were his principles universally and steadily to prevail... [a]ll discourse... would immediately cease... (Hume 1748, XII: II, 119)

The skeptic about intuitions is also likely to hear the same worry. Her arguments can, ultimately, have little effect, for, as a pragmatic matter of fact, philosophers have nothing else to appeal to when it comes to securing ultimate premises. As Timothy Williamson (2007) says:

When contemporary analytic philosophers run out of arguments, they appeal to intuitions. It can seem, and is sometimes said, that any philosophical dispute, when pushed back far enough, turns into a conflict of intuitions about ultimate premises: "In the end, all we have to go on is our intuitions." (Williamson 2007, 214)

Accordingly, Williamson suggests that we:

...proceed on the working hypothesis that evidence plays a role in philosophy not radically different from its role in all other intellectual disciplines. Without such a role, what would entitle philosophy to be regarded as a discipline at all. (Williamson 2007, 214, original emphasis)

Similarly, here is Janet Levin (2004), recapitulating an argument she finds in Bealer: 
the first premise [is] that, without appeal to the reliability of some source of extra-empirical evidence, we can have no grounds whatsoever for modal, epistemic, or other normative claims, the second that intuitions of the sort described are the best candidates for such evidence. (Levin 2004, 198)

Levin calls this 'the Argument from Need.' We take it that the argument can be unpacked as follows:

Stage 1

1. If we have no reliable extra-empirical source of evidence, then we cannot have any grounds whatsoever for philosophical claims such as those about modality, epistemology, or other normative claims.

2. Surely, we can have some grounds for such claims.

3. Hence, we have some reliable extra-empirical source of evidence.

\section{Stage 2}

4. Philosophical intuitions are the best candidates for being a reliable extra-empirical source of evidence.

5. Hence, philosophical intuitions are a reliable extra-empirical source of evidence.

Some anti-evidentialists may simply reject premise (2)-holding that there really are no grounds for modal, epistemic, and normative claims. However, depending upon what is meant by 'grounds', such skepticism may not be necessary. For we could grant that there are "grounds" for such claims-in the sense that there are non-arbitrary reasons to make those claims rather than some others-yet deny that these grounds are evidential. This is what we mean to do. We maintain that philosophy is not reliant, ultimately, upon intuitive evidence (and this serves as our second response to the self-defeating argument - that our skepticism about the evidential status of intuitions is, though based upon intuitions, not evidentially based upon intuitions). We concede that, ultimately, arguments may appeal to intuitions; we concede that intuitions may play a role in giving rise to beliefs about metaphysical, modal, ethical and epistemic matters of fact; we concede, moreover, that intuitions give rise to beliefs with the same content-i.e. an intuition that $\mathrm{P}$ gives rise to a belief that $\mathrm{P}$, not a belief that $\mathrm{Q} ;$ but we do not concede that

5 (Levin 2004). Levin claims to find it in Bealer (2000, 7), but the citation she gives leads to an "intuition-skepticism is self-defeating" type argument, of the sort we sketched by Pust. Still, the argument from need, pretty much the way Levin writes it, does the rounds. 
intuitions are thereby deployed as evidence. Getting clear on this claim, then, and showing how it answers many of the problems that have already been raised, is the principal aim of the next section.

\section{Intuitions as Inclinations to Believe}

\subsection{The Initial Plausibility of Our Thesis}

Harry the philosopher has several strong but brute inclinations to believe. Namely, he is strongly inclined to believe P, Q, R and S. As it happens, the other philosophers in Harry's community are, with few exceptions, also inclined to believe the same propositions. Strangely, none of the philosophers has any introspective access to why they are so inclined. In fact, none of them can think of an argument for P, Q, R or S that does not rest on less appealing premises. Hence, they do not give arguments for the four propositions. Nevertheless, most philosophers believe P, Q, R and S and use them in premises for other arguments. Positions, moreover, that entail the negations of these four are generally taken to be bad. Harry, for instance, has made a career writing papers showing that theory $\mathrm{T}$ or $\mathrm{T}^{\star}$ is false because it entails either $\sim \mathrm{P}, \sim \mathrm{Q}, \sim \mathrm{R}$, or $\sim \mathrm{S}$. Here and there are philosophers-often those who support $\mathrm{T}$ or $\mathrm{T}^{*}$ - who deny $\mathrm{P}, \mathrm{Q}, \mathrm{R}$ or $\mathrm{S}$ and insist that Harry provide an argument. Harry cannot, but he has not much time for such people anyway, for when they claim not to believe P, Q, R or S, Harry secretly regards them as liars.

On the face of it, Harry's inscrutable inclinations to believe behave a lot like intuitions. Moreover, when Harry introspects his inscrutable inclinations to believe he finds nothing that differs from a strong intuition. So here we have a plausible conjecture; intuitions are a kind of inclination to believe. In the next subsection we see how the conjecture answers the problems raised for intuitions in general.

\subsection{Taking Care of the Explananda}

We maintain that intuitions, being inclinations to believe, are not used as evidence in philosophy. But if they are not then why do they appear to be so used? Specifically:

How do intuitions give rise to beliefs if they do not provide evidence for them? Moreover, if they are not evidential, why do intuitions that $\mathrm{P}$ give rise to beliefs that $\mathrm{P}$, not beliefs in some arbitrary $\mathrm{Q}$ ?

Why do agents appeal to intuitions in accounting for their beliefs?when asked why one believes that $\mathrm{P}$, why is it appropriate to reply that one finds $\mathrm{P}$ intuitive? 
How have non-evidential intuitions been deployed so successfully in philosophical argument?

In answer, we maintain that intuitions are a kind of inclination to believe. It is therefore not surprising that they lead to beliefs. After all, it is a brute psychological fact that S's (occurrent) inclination to X leads, typically, given opportunity, ability and a lack of opposing inclinations, to S's X-ing. For example, an inclination to go to bed leads, given a lack of opposing inclinations, to one going to bed, provided one is able. Hence, it is no mystery that S's inclination to believe that $\mathrm{P}$ leads, typically, given opportunity, ability and a lack of opposing inclinations, to S's believing that $\mathrm{P}$. The connection between the inclination to believe and the subsequent believing is the same connection we see between any inclination to $\mathrm{X}$ and the subsequent Xing.

Note that the account is merely causal, as opposed to inferential. Causal accounts, however, must answer the following question: Why is it that the intuition that $\mathrm{P}$, in merely causing the subsequent belief, causes a belief that $P$, not some other belief with arbitrary content Q? I.e. what is the mechanism of content preservation? If the transition from input to output was an inference, rather than mere causation, then output would thereby be constrained to be content-related to the input. But since, on our view, the transition is not inferential, but the inputs and outputs are still content-related (indeed, content identical), what is providing the relevant constraint?

The inclinations to believe thesis meets this demand. For on our account, an intuition that $\mathrm{P}$ is an inclination to believe $P$, not anything else, so one satisfies the inclination only by adopting a belief with the content $P$. That is why intuitions that $\mathrm{P}$ give rise to beliefs with the same content. Content preservation is non-mysterious on our account.

The second explanandum is also readily taken care of. One can account for one's belief by appealing to one's intuitions because an intuition is an inclination to believe, hence:

I believe $\mathrm{P}$ because I find $\mathrm{P}$ intuitive

is akin to:

I believe $\mathrm{P}$ because I am inclined to believe $\mathrm{P}$.

In this way, the appeal to intuitions is classified as a form of praxic reasongiving: The agent is asked why she is taking a certain action and she responds by saying that she is inclined to. We give answers like this all the time, whether we are accounting for why we chose the soup over the salad (because I am inclined towards the soup) or accounting for why we holidayed in Portugal rather than Mexico (I am inclined towards Portugal) or 
whatever. Though one might have hoped for something more illuminating, such answers are nonetheless conversationally adequate. They are (minimal) positive responses to requests for praxic reasons-requests for the motivation of action. In the same way, we regard the holding of a belief as an ongoing choice on the part of the believer and the question of why one holds the belief as a request for the motivation for the choice. The answer 'because I intuit it'-being equal to the minimal positive response 'because I am inclined to believe it' - meets the norms for praxic reason giving. Though, as before, one might have hoped for something more illuminating, as before, the answer is nonetheless conversationally adequate.

Finally, we can explain how non-evidential intuitions have been deployed so successfully in philosophical argument. For the propositional contents of strong intuitions are thereby the targets of strong inclinations to believe, and so they stand as persuasive premises in arguments. If Jones bases her argument on $\mathrm{P}$, for example, and everyone she aims to convince has a strong inclination to believe that $\mathrm{P}$ (and-even better-no competing inclination to believe otherwise) then Jones' argument is likely to be successful. That does not make inclinations to believe into evidence. Nor does it mean that Jones's conclusion is justified. But the argument Jones ran is based on a proposition people are inclined to believe and so-as a psycho-social matter of fact-it will be convincing. And that is all one needs to run an effective argument.

Lastly, and most importantly, the position gives us a clear path through the dilemma raised in the earlier part of the paper; namely, that either philosophers who claim to be working on troublingly extra-mental entities really are trying to do that, but they are using tools which, by any account we can imagine, are unsuited to the task, or they are engaged in some suitably conservative business of concept explication, or something similar, in which case those who take themselves to be working on extra-mental matters are flagrantly confused about the targets of their investigation. The trouble arises, we think, only if intuitions are taken to be both directed towards troublingly extra-mental affairs and evidential. But on the inclination-tobelieve view, they play their role in philosophical methodology by being persuasive, not by being evidential or truth indicative. As a result, they can be about any extra-mental thing you like. It is only important, in getting the rhetorical job done, that they be shared; not that they be right, appropriately related to their objects or reliably formed.

\subsection{Could Inclinations to Believe Be Forms of Evidence?}

None of which is to say that inclinations to believe could not ever be truth indicative. We claim only that they need not be, in order to explain their deployment in philosophical method. Their role as persuaders, and hence 
as the bases of arguments, is accounted for by their being identified with a sub-class of generally held inclinations to believe. Those intuitions that are generally held inclinations to believe will be persuasive. Those that are rare and idiosyncratic will prompt only puzzled stares.

Still one wants to ask: Are our inclinations to believe truth indicative? The proposition is plausible. Our inclination to eat sugar emerges from an evolutionary history throughout which energy was in short supply. Similarly, our inclinations to believe may be based in processes that reliably led to survival, reproductive success and good things quite generally. If so, then there is prima facie reason to expect that one's epistemic instincts are worth attending to, and there is no denying that inclinations to believe are often the starting point of productive lines of inquiry.

However, we suspect that intuitions, though psychologically homogeneous -i.e. all belonging to the class of inclinations to believe-are probably nonetheless epistemically heterogeneous - i.e. reliable to radically different extents thanks to having radically different connections to their objects. We suspect this not because we have any direct evidence for it but because it is prima facie unlikely that our metaphysical, modal, moral, epistemic and semantic inclinations to believe are all connected to the truth via a single consistently reliable mechanism, given that the abstract and concrete, actual and nonactual targets of those intuitions are so diverse. But if our intuitions connect to their truth-makers via different mechanisms (or, as a special case, if they do not connect at all) then they are therefore reliable (or not) to radically different extents.

(This, of course, raises another problem for the evidentialist, for she can explain the fact that intuitions are more or less equally persuasive across subdisciplines only by supposing that they are more or less equally evidential. Given that intuitions are almost certainly epistemically diverse-admitting of great variation in the reliability of their connection to the facts-this is prima facie unlikely. But the alternative to this is that intuitions are uniformly psychologically persuasive despite being epistemically diverse, which means that their persuasiveness is not a function of their epistemic worth, but of their psychological strength across a range of individuals. But once this is conceded, why bother to suppose that they are evidential at all? Their action in the philosophical community is entirely explained by their psychological effect.)

\section{Objections to the Positive Account}

\subsection{Competitive vs. Net Inclinations}

Here's a central objection to our proposal: There at least appear to be cases where one has an intuition without an accompanying inclination to believe. 
It seems coherent, that is, to claim:

(i) I have an intuition that $\mathrm{P}$ but I am not inclined to believe it.

One thinks of the naïve comprehension axiom: One might find it intuitive while having no inclination to believe it. ${ }^{6}$ Hence, it would seem, our thesis is mistaken. For there is no way that one can have an intuition that $\mathrm{P}$ without an accompanying inclination to believe if intuitions are inclinations to believe (of some sort.) ${ }^{7}$

This objection can be met by making a distinction between net and competitive inclinations. ${ }^{8}$ Competitive inclinations can be co-occurrent in the agent-for example, one can have a competitive inclination to eat the cake and a simultaneous competitive inclination to stay on one's diet. Net inclinations, on the other hand, are what is left once the competitive inclinations fight it out. The net inclination is the winner of the fight. In the end, then, one either has a net inclination to eat the cake (and, ceteris paribus, one goes ahead) or one does not (and, ceteris paribus, one does not.)

Accordingly, one can account for the apparent ability of intuitions to part from inclinations to believe by regarding the former as a species of competitive inclination. That way, one can read (i) as follows:

(ii) I have an intuition that $\mathrm{P}$ but no net inclination to believe it.

And substituting a competitive inclination to believe in for the intuition, the proper reading of (ii) (and therefore (i)) becomes:

(iii) I have a competitive inclination to believe that $\mathrm{P}$ but no net inclination to believe it.

But that is clearly possible since one can have a competitive inclination to believe without an accompanying net inclination, simply when the competitive inclination fails to win out. So one might have an intuition (i.e. a competitive inclination to believe) that the naive comprehension axiom is true that

6 The example, used to slightly different effect, appears in (Bealer 1992) and elsewhere. Bealer credits the example to George Myro (Bealer 1992, 130). Plantinga $(1993,110)$ also notes that intuitions linger beyond refutation. Kagan (1989) argues that some moral intuitions are informationally encapsulated, i.e. tolerant of opposing beliefs. See (Pust 2000, 34-35) for discussion.

7 Robert May and Adam Sennet each—on separate occasions-brought this objection to our attention. We thank both for helping us clarify our position.

8 Robert Cummins (1998) argues that intuitions change via reflective equilibrium (RE). I.e. via a process of continual and mutual readjustment between intuition, theory and data. Cummins' view is quite compatible with our own, according to which adjustments to intuition are nothing more than adjustments to the relevant competing inclinations. 
is opposed by an overwhelming (competitive) inclination to believe the opposite (arising from Russell's proof). This results in a net inclination against believing in the axiom resulting in the situation expressed in (iii). ${ }^{9}$

\subsection{The Episodic Objection}

Focusing on the work of Ernest Sosa (1998), Pust (2000) argues that inclination/disposition-to-believe views fail to capture the occurrent nature of intuitions, and that attempts to patch them up run into further difficulties. Bealer (1998), in similar fashion, argues as follows:

9 Still, a determined opponent might claim that the following is coherent:

(iv) I have an intuition that $\mathrm{P}$ but no competitive inclination to believe that $\mathrm{P}$.

Our thesis is incompatible with any true claim of this sort. However, it is not obvious that there are real cases like this. In fact, there are good reasons to think there are not, for note that there are obviously cases like (v):

(v) I have an intuition that $\mathrm{P}$ but no competitive inclination to not believe that $\mathrm{P}$.

For instance, one has a strong intuition that everything has the same properties as itself, and one has no way to doubt it. There are also clear cases of the following:

(vi) I have no competitive inclination to believe that $\mathrm{P}$ and no competitive inclination to not believe that $\mathrm{P}$.

Trivially, such cases occur when one has not contemplated $\mathrm{P}$ at all, or where the proposition in question is an empirical matter of little importance about which one is utterly uninformed. Given that there are cases of (v) and (vi), and also given (we are granting for reductio) that cases like (iv) exist, there ought to be cases where the three are combined to make:

(vii) I have an intuition that $\mathrm{P}$ yet no competitive inclination to believe that $\mathrm{P}$ and no competitive inclination to not believe that $\mathrm{P}$.

For the fact that there are cases of (iv) means that the first two conjuncts of (vii) are compatible, and the fact that there are cases of (v) means that (the first and third conjuncts of (vii)) are also compatible; and the fact that there are cases of (vi) means, in the same fashion, that the second and third conjuncts of (vii)) are compatible too. So we should have cases of (vii) because (ceteris paribus) we should have (at least possible) cases of $\mathrm{A} \wedge \mathrm{B} \wedge \mathrm{C}$ whenever we have cases of $\mathrm{A} \wedge \mathrm{B}, \mathrm{A} \wedge \mathrm{C}$ and $\mathrm{B} \wedge \mathrm{C}$. But there are no cases of (vii)! There are no cases in which one has an intuition that $\mathrm{P}$ and yet-despite there being no inclination to resist it -there is still no inclination to believe that $\mathrm{P}$. And it is not even clear that there are possible cases. For the mind boggles at what it would be like to find a proposition intuitive and yet, despite a lack of any reason to doubt it, have no inclination to believe it whatsoever. Hence, given the clear existence of cases of (v) and (vi), the lack of possible cases of (vii) is surprising unless there are no cases of (iv). Hence we have some reason to doubt that cases of (iv) are possible. 
As I am writing this, I have spontaneous inclinations to believe countless things about, say, numbers. But at this very moment I am having no intuition about numbers. I am trying to write, and that is about all I can do at once; my mind is full. If I am to have an intuition about numbers, then above and beyond a mere inclination, something else must happen - a sui generis cognitive episode must occur. Inclinations to believe are simply not episodic in this way. (Bealer 1998, 209)

In brief, then, intuitions are episodic; inclinations to believe are not; hence intuitions are not inclinations to believe.

We do not concede, however, that intuitions are always (or even usually) occurrent or episodic. The most compelling reason to think otherwise comes from considering the truth conditions of intuition statements: For if one claims at $\mathrm{t}$ that Gettier has an intuition that $\mathrm{P}$ then what one says is true if $\mathrm{P}$ is something that Gettier generally intuits, regardless of what occurrent state he happens to be in at t. It really does not matter for example if, at the time of the utterance, Gettier is asleep and having no episodic mental states with content $\mathrm{P}$. One would truly say he intuits $\mathrm{P}$ nonetheless. But, surely, 'Gettier intuits that P' is true only if Gettier intuits that P. Hence, when one says, truly, while he is asleep, that Gettier intuits that $P$ then, since one said it truly, it follows that he intuits that P, despite the lack of any episodic mental state with the content $\mathrm{P}$. But if he can intuit that $\mathrm{P}$ without there being any episodic mental state with the content $\mathrm{P}$ then it follows that intuiting that $\mathrm{P}$ is not an episodic mental state.

Why, then, would anyone think that intuitions are episodic? Presumably because we are aware of having an intuition only when we are experiencing episodic consciousness of it. However, to conclude from this that they are always occurrent is to commit the "refrigerator-light fallacy": To confuse that which is always the case when you are looking with that which is always the case. Of course, intuitions are always episodic when we have them episodically. What about when we are not having one episodically? In that case, it might appear, from introspection alone, that the intuition is absent. In fact, however, it is merely non-occurrent.

\subsection{Some Inclinations to Believe are Not Intuitions}

Consider the following objection to intuitions being inclinations to believe, which comes from Bealer:

Consider a posteriori necessities that...lie beyond the reach of our rational intuition: for example, that gold has atomic number 79, that heat involves microscopic motion, and so forth. Presumably, by suitably modifying the brain we could cause a subject to acquire the sort of spontaneous inclination [to believe] featured in the proposed re- 
duction. We could, for example, cause someone to have a spontaneous inclination to believe that gold has atomic number $79 \ldots$ But the person would still not be able to intuit these necessities, for in that case they would be a priori, not a posteriori, as everyone takes them to be.

For Bealer, an intuition can only have as its target an a priori proposition. But an inclination to believe can have anything as its target. Hence intuitions cannot simply be inclinations to believe.

However, this is compatible with our thesis. For we only claim that intuitions are a kind of inclination to believe. Hence we can concede, for the sake of argument, that all intuitions concern the a priori, in which case the class of intuitions is some appropriate sub-class of the set of inclinations to believe; one whose members only concern the a priori. Thus, when the neurosurgeon implants an inclination to believe that $\mathrm{P}$, where $\mathrm{P}$ is an a posteriori truth, it follows that that inclination to believe is not an intuition. Bealer's counterexample, therefore, fails to threaten our project.

\section{Further Directions}

One may reasonably ask, however, about the remainder of the account. If intuitions are only a kind of inclination to believe, then what kind exactly are they? Right now, we have no precise answer. However, we would resist any suggestion that this renders the project uninformative. For one thing, our project is strictly at odds with other projects that count intuitions as forms of evidence, intellectual seemings, abstractions from background beliefs, judgments (see Earlenbaugh and Molyneux 2009) and so on. So we are obviously making a substantial claim. More importantly, though, we think that worthwhile work is done when one reaps an explanatory reward from correctly locating a kind in the overall taxonomy. For instance, if one derives an explanatory reward from classifying a platypus as a mammal then one thereby makes a useful contribution, even if there is still the open question "Exactly what kind of mammal is a platypus that makes it distinct from all others?" Similarly, we get an explanatory pay-off from classifying intuitions as inclinations to believe for we are able to explain how it is that intuitions play the role in philosophical method that they do without having to posit some strange truth detecting relation between mental states and the deepest most austere facts about reality. There is, of course, a residual question"Exactly what kind of inclination to believe are intuitions?" but it is one that can wait.

Ultimately, of course, it will be important to determine what kind of inclinations to believe intuitions are. Perhaps Bealer is right that intuitions are marked by their connection to the a priori. As we just argued, that is com- 
patible with our view (however, it excludes kinds of inclinations to believe that, it seems to us, are also best classed as intuitions). Alternatively, perhaps the distinguishing feature of intuitions is their relative inscrutability. With other inclinations to believe we usually have a good idea why we have the inclination. I might be inclined to believe what is right before my eyes, for example, but that is because of the potency of the sensory data; I might be inclined to believe in a pleasant afterlife simply because it is seems comforting to me. But in that case, again, I know why I am inclined to believe it. It is often much harder, with intuitions, to say why we believe what we do. So perhaps this is the hallmark of the intuition, what distinguishes it from other inclinations to believe. At this point in time, the correct answer is unclear.

\section{Acknowledgments}

General thanks for helpful discussion go to fellow members of our department at the University of California at Davis, participants at the 2008 Meeting for the Society for Exact Philosophy and participants at the 2008 Bellingham Summer Philosophy Conference. Special thanks go to Magdalena Balcerak, Elizabeth Barnes, John Bengson, Dustin Locke, Marc Moffett, Adam Sennet, Brian Weatherson, Jonathan Weinberg and an anonymous reviewer for extended or written feedback on material related to this paper.

\section{Bibliography}

Bealer, G. (1992). The incoherence of empiricism, Proceedings of the Aristotelian Society Supp. 66: 99-143.

Bealer, G. (1998). Intuition and the autonomy of philosophy, in DePaul and Ramsey (eds), Rethinking Intuition: The Psychology of Intuition and its Role in Philosophical Inquiry, Rowman and Littlefield Publishers, Inc, Maryland, pp. 201-239.

Bealer, G. (2000). A theory of the a priori, Pacific Philosophical Quarterly 81: 1-30.

Benacerraf, P. (1973). Mathematical truth, Journal of Philosophy 70: 661-679.

Cummins, R. (1998). Reflections on reflective equilibrium, in DePaul and Ramsey (eds), Rethinking Intuition: The Psychology of Intuition and its Role in Philosophical Inquiry, Rowman and Littlefield Publishers, Inc, Maryland, pp. 113-127.

Earlenbaugh, J. and Molyneux, B. (2009). Intuitions are inclinations to believe, Philosophical Studies 145: 89-109. 
Goldman (1992). Cognition and modal metaphysics, Liaisons: Philosophy Meets the Cognitive and Social Sciences, MIT Press, Cambridge, MA, pp. 49-66.

Goldman, A. (1987). Cognitive science and metaphysics, Journal of Philosophy 84: 537-544.

Goldman, A. (2007). Philosophical intuitions: Their target, their source and their epistemic status, Grazer Philosophische Studien 74: 1-26.

Goldman, A. and Pust, J. (1998). Philosophical theory and intuitional evidence, in DePaul and Ramsey (eds), Rethinking Intuition: The Psychology of Intuition and its Role in Philosophical Inquiry, Rowman and Littlefield Publishers, Inc, Maryland, pp. 179-200.

Hume, D. (1748). An Enquiry Concerning Human Understanding. Republished 2008 by Forgotten Books. www.forgottenbooks.org.

Hume, D. (1896). A Treatise on Human Nature, NuVision Publications.

Kagan, S. (1989). The Limits of Morality, Oxford University Press, New York.

Kornblith, H. (1998). The role of intuition in philosophical inquiry: An account with no unnatural ingredients, in DePaul and Ramsey (eds), Rethinking Intuition: The Psychology of Intuition and its Role in Philosophical Inquiry, Rowman and Littlefield Publishers, Inc, Maryland, pp. 129-141.

Levin, J. (2004). The evidential status of philosophical intuition, Philosophical Studies 121: 193-224.

Plantinga, A. (1993). Warrant and proper function, Oxford University Press, New York.

Pust, J. (200o). Intuitions as Evidence, Garlan, New York.

Pust, J. (2001). Against explanationist skepticism concerning philosophical intuitions, Philosophical Studies 106: 227-258.

Sider, T. (2001). Four-dimensionalism: An Ontology of Persistence and Time, Clarendon Press, Oxford.

Sosa, E. (1998). Minimal intuition, in DePaul and Ramsey (eds), Rethinking Intuition: The Psychology of Intuition and its Role in Philosophical Inquiry, Rowman and Littlefield Publishers, Maryland, pp. 257-270.

Strawson, P. F. (1959). Individuals, Methuen, London.

Williamson, T. (2007). The Philosophy of Philosophy, Blackwell, Oxford. 